Article

\title{
Optimized Culture Conditions for the Detection of Selected Strains of Bacillus in Eye Creams
}

\author{
Nadine Yossa ${ }^{1, *}$, Gabriela Arce ${ }^{1}$, James Smiley ${ }^{1}$, Mei-Chiung Jo Huang ${ }^{2}$, Lanlan Yin ${ }^{3}$, \\ Rebecca Bell ${ }^{4}$, Sandra Tallent ${ }^{4}$, Eric Brown ${ }^{4}$ and Thomas Hammack ${ }^{4, *}$ \\ 1 Oak Ridge Institute for Science and Education, Oak Ridge, TN 37831, USA; Carolina2052@yahoo.com (G.A.); \\ James.Smiley@fda.hhs.gov (J.S.) \\ 2 U.S. Food and Drug Administration, Office of Cosmetics and Colors, College Park, MD 20740, USA; \\ Jo.Huang@fda.hhs.gov \\ 3 U.S. Food and Drug Administration, Office of Analytics and Outreach; College Park, MD 20740, USA; \\ Lanlan.Yin@fda.hhs.gov \\ 4 U.S. Food and Drug Administration, Office of Regulatory Science, College Park, MD 20740, USA; \\ Rebecca.Bell@fda.hhs.gov (R.B.); Sandra.Tallent@fda.hhs.gov (S.T.); Eric.Brown@fda.hhs.gov (E.B.) \\ * Correspondences: IreneNadine.Tchagou@fda.hhs.gov (N.Y.); Thomas.Hammack@fda.hhs.gov (T.H.); \\ Tel.: +1-240-402-1072 (N.Y.); +1-240-402-2010 (T.H.); Fax: +1-301-436-1055 (T.H.)
}

Received: 16 August 2017; Accepted: 11 December 2017; Published: 16 December 2017

\begin{abstract}
Although eye area cosmetics contain preservatives, contamination can still occur during or after manufacture or through use. Understanding the likelihood of bacterial survival in eye creams begins with sensitive and accurate methods for the detection of bacterial contamination; therefore, we investigated optimal culture conditions, including neutralizers, dilution broths, and selective media for the detection of Bacillus in eye cream. Samples of three different brands of eye creams were first mixed with Tween 80, Tween 20, or a blend of Tween 60 and Span 80, then neutralized and non-neutralized samples were individually inoculated with B. cereus strains, B. mycoides, a mislabeled B. megaterium, B. subtilis or B. thuringiensis at a final concentration of $5 \log C F U / g$. The inoculated samples, with and without neutralizers, were spiral-plated and incubated at $30{ }^{\circ} \mathrm{C}$ for $24 \mathrm{~h}$ to 48 h. Presumptive colonies of Bacillus were enumerated on U. S. Food and Drug Administration Bacteriological Analytical Manual (FDA-BAM) referenced agars Bacillus cereus rapid agar (BACARA) and mannitol-egg yolk-polymixin agar (MYP). Our results show significant differences among the neutralizers, plates, and products. The combination of Tryptone- Azolectin-Tween and Tween 80 (TAT and T80) produced higher levels of Bacillus, estimated at $4.18 \mathrm{log}$ CFU/g compared to growth on Modified letheen broth and Tween 80, which produced $3.97 \log$ CFU/g $(P<0.05)$. Colony counts of $B$. cereus cells on MYP agar were significantly higher, than those on BACARA agar, showing an average of $4.25 \log \mathrm{CFU} / \mathrm{g}$ versus $3.84 \mathrm{log} \mathrm{CFU} / \mathrm{g}$, respectively $(P<0.05)$. The growth of the strain mislabeled B. megaterium ATCC 6458 on B. cereus selective agars BACARA and MYP agar led us to further investigations. We identified bi-pyramidal crystals among colonies of the strain, and subsequent PCR identified the cry 1 gene, indicating that strain was actually $B$. thuringiensis subps. kurstaki.
\end{abstract}

Keywords: Bacillus cereus; detection; eye cream

\section{Introduction}

Although eye area cosmetics contain preservatives, contamination can still occur during or after manufacture or through use. Microbial contamination has been the cause of product recalls $[1,2]$. The presence of antimicrobial preservatives in cosmetics makes it difficult to detect and isolate microorganisms. Understanding the effects of preservatives on the growth of target organisms 
in enrichment media and on selective/differential plating agars is essential for the detection of pathogenic organisms in cosmetics. Microorganisms indigenous to the normal eye, significant isolates, and products isolates are recommended by the Personal Care Products Council for challenging eye cosmetics; these include Gram-positive spore former bacteria [3]. This research focusses on the detection and isolation of Bacillus spp. in eye area cosmetics. Bacillus species are Gram-positive rod-shaped bacteria that are widely found in the environment, such as soil, dust, water, and sediments. Bacillus cereus group is a subdivision of the Bacillus genus; the group currently comprises eight closely genetically related species that are formally recognized: $B$. cereus, $B$. thuringiensis, $B$. weihenstephanensis, B. mycoides, B. anthracis, B. toyonensis, B. cytotoxicus, and B. pseudomycoides [4]. "Presumptive B. cereus is the name utilized by ISO 7932:2005 and ISO 21871:2006 [5,6] in order to acknowledge the fact that the confirmatory stage does not enable the distinction of B. cereus from other members of the group on the surface of a selective culture medium. The bacterium exists as a spore former and vegetative cell in nature and as a vegetative when colonizing the human body. Vegetative cells of $B$. cereus produce a range of toxic enzymes responsible for gastrointestinal and non-gastrointestinal diseases by tissue destruction [7]. B. cereus is a rare but significant pathogen of the eye that can lead from mild to severe infections, and to severe endophthalmitis often resulting in the loss of the vision [8]. Cases of inflammation of the eye cornea (keratitis) have been reported to be linked with the use of contact lenses contaminated with B. subtilis and cereus [9-11]. Several eye-area cosmetic products contaminated with Bacillus species included the members of Bacillus cereus group (cereus and thuringiensis) have been recalled [12,13], however, there are currently no reports of eye infections associated with eye-area cosmetic products contaminated with Bacillus species. Besides the fact that $B$. cereus could be a potential threat to the user if all the key factors are present, all Bacillus species could also affect the integrity of cosmetic products [14].

Spores are resistant to extreme environments and may have been unaffected by the product formulation, therefore, vegetative cells were preferred in this study: We explored the optimum culture conditions for the detection and isolation of B cereus F 4227A, B. cereus F 6006, B. cereus ATCC 14579, B. megaterium ATCC 6458, B. mycoides ATCC 6462, B. subtilis ATCC 15563, and B. thuringiensis ATCC 35866 individually spiked into eye cream products (coded B, C and D) preserved differently (Table 1), for these tests. Products B and D used more conventional preservative ingredients, such as parabens, sodium benzoate, or potassium sorbate, while Product C was composed of $90 \%$ organic ingredients. Nonionic surfactants such as sorbitan esters (i.e., Spans) and polysorbates (i.e., Tweens) are used as emulsifiers, solubilizers, wetting agents and in number of applications [15]. In addition, to encourage the growth of bacteria in substances that contain conventional biocides, Spans and Tweens are used to neutralize the action of many biocides including parabens, sodium benzoate, potassium sorbate, phenolics, organic acids and esters, Tego compounds (amphoteric, ampholytic surface active agents), and iodine [16,17]. For this project, we evaluated the effectiveness of Tween 80 (T80), Tween 20 (T20) and a mixture of Tween 60 and Span 80 (TS) because these have been recognized to neutralize the effects of most preservatives. Modified letheen broth (MLB) and Tryptone-Azolectin-Tween (TAT) were tested as diluents. Finally, we used the selective plating media of B. cereus, BACARA and Mannitol Yolk Polymyxin (MYP) agars for the isolation and enumeration of Bacillus cereus, as recommended by the FDA-BAM [18].

An unexpected part of our research was identifying a mis-labeled strain. The strain mislabeled B. megaterium ATCC 6458 grew on agars meant to be selective for Bacillus cereus; therefore, we employed microscopic and molecular methods to determine the correct identifier for that bacterium.

\section{Materials and Methods}

\subsection{Cosmetic Samples:}

Eye cream products $(N=527) B, C$, and D were purchased online and from multiple retail stores. All products were kept at the laboratory in their original containers, at room temperature. These 
eye creams used a variety of preservation techniques; some ingredients were plant-based substances known to have antimicrobial activities, and others were conventional preservatives. Product D used both types of preservatives. Table 1 is a representation of the antimicrobial agents from the products. The packaging of the eye creams did not indicate a period of durability for these products.

Table 1. Preservatives and ingredients with antimicrobial properties found in the eye creams from three different manufacturers (Products B, C, and D).

\begin{tabular}{ccc}
\hline Product B & Product C (Organic) & Product D \\
\hline Bisabolol & Aloe barbadensis & Camellia sinensis leaf \\
Diazolidinyl Urea & Aspalathus lineans & Citric acid \\
Methylparaben & Calendula officinalis & Potassium sorbate \\
Propylparaben & Citric acid & Sodium benzoate \\
& Lavendula angustifolia & \\
& Oenotheris biennis \\
& Olea europea & \\
& Punica granatum \\
Rhodiola Roots & \\
& Simmondsia chinensis \\
\hline
\end{tabular}

Product C: 90\% organic; Products B and D contain conventional preservatives.

\subsection{Preparation of Bacterial Strains}

Five different Bacillus spp. were used for this study: 3 strains of B. cereus and 1 each of B. mycoides, B. subtilis, B. thuringiensis, and B. megaterium. The strains and their origins are listed in Table 2. All cultures were maintained at $-80{ }^{\circ} \mathrm{C}$ in $20 \%$ glycerol. Each strain was aseptically sub-cultured into Nutrient Broth (NB, pH 7.2) (Difco ${ }^{\mathrm{TM}}$, Franklin Lakes, NJ, USA) for $24 \mathrm{~h}$ at $30^{\circ} \mathrm{C}$ and stored at $4{ }^{\circ} \mathrm{C}$ for use. Prior to each experiment, cultures were grown in $\mathrm{NB}$ and incubated at $30{ }^{\circ} \mathrm{C}$ for $24 \mathrm{~h}$. Cells were centrifuged $\left(7500 \times g, 10 \mathrm{~min}, 4^{\circ} \mathrm{C}\right)$, then washed twice in phosphate buffered saline (PBS) $\left(\mathrm{Difco}{ }^{\mathrm{TM}}\right)$. The cell pellets were resuspended in PBS and the cell density of each strain was adjusted to obtain final concentration $\sim 7 \log$ CFU / mL. The count of each strain was verified on Tryptic soy agar (TSA) $\left(\right.$ Difco $\left.^{\mathrm{TM}}\right)$ by spiral plating technique.

Table 2. Bacillus spp. used in this study.

\begin{tabular}{cc}
\hline Bacillus spp. & Strain ID \\
\hline B. cereus & F 4227 A \\
B. cereus & F 60006 \\
B. cereus & ATCC 14579 \\
B. mycoides & ATCC 6264 \\
B. thuringiensis & ATCC 35866 \\
B. megaterium & ATCC 6458 \\
B. subtilis & ATCC 15563 \\
\hline
\end{tabular}

F: indicates foodborne outbreak isolates from the U.S. Food and Drug Administration Center for Food Safety and Applied Nutrition culture collection (FDA CFSAN), provided by Sandra Tallent. ATCC: purchased from American Type Culture Collection (ATCC) (Manassas, VA).

\subsection{Sample Preparation and Inoculation}

Twenty grams of each eye cream were placed into sterile individual $50 \mathrm{~mL}$ polystyrene Falcon tubes, along with one of the following: 1) $20 \mathrm{~mL}$ of Tween 20, $20 \mathrm{~mL}$ of 50\% Tween 80, or $20 \mathrm{~mL}$ of TS, 2) a blend of $10 \mathrm{~mL}$ of 20\% Tween 60 (Fisher Thermo Scientific Inc., Pittsburgh, PA, USA), and 3) $10 \mathrm{~mL}$ of Span 80 (TS; Sigma-Aldrich Co. LLC, St Louis, MO, USA). We added glass beads to each tube, mixing thoroughly to obtain good homogenization and neutralization. Then $200 \mu \mathrm{L}$ of fresh Bacillus culture was individually added to both the homogenized/neutralized and the non-neutralized 
samples to obtain $\sim 5 \log$ CFU/g cream. Each of the samples was vortexed to mix thoroughly and then maintained at room temperature $\left(\sim 15^{\circ} \mathrm{C}\right)$ for $30 \mathrm{~min}$.

\subsection{Enumeration of Bacillus}

After the exposure-time, $1 \mathrm{~mL}$ of each artificially contaminated sample was placed into a sterile $15 \mathrm{~mL}$ Falcon conical tube along with $9 \mathrm{~mL}$ of sterile Modified letheen broth (MLB) and TryptoneAzolectin-Tween (TAT) broth (Difco ${ }^{\mathrm{TM}}$ ). After thorough mixing, appropriately diluted suspensions were spiral plated (WASP 2, Microbiology International, Frederick, MD, USA) on BACARA (BACARA, Biomerieux, Durham, NC, USA) and Mannitol Yolk Polymyxin (MYP, Oxoid, Basingstoke, UK) agars. The inoculated samples that had not undergone neutralizing treatment were spiral-plated on modified letheen agar (MLA; Difco ${ }^{\mathrm{TM}}$ ) following the modified method M-4 from the Personal Care Products Council [19]. Most probable number (MPN) method was used for samples presenting no growth on the plates [20]. A typical characteristic of the member of B. cereus group is an orange or pink color surrounded with a white halo on BACARA or MYP, respectively. The strain labelled B. megaterium showed that feature and led us to further investigation.

\subsection{Testing for Protein Crystals in the Mislabeled Strain Using Two Staining Methods}

First, an aliquot from a sporulated colony of purported B. megaterium was transferred to a microscope slide and the FDA-BAM staining procedure was followed [21]. To confirm the identification, we also used a modified method as follows [22]: A smear of purported B. megaterium was mixed with sterile water on a microscope slide which was then brought to boiling over the flame without burning, flooded with methanol, and air-dried. Next, we placed drops of $0.133 \%$ of brilliant blue R-250 (Fisher) dissolved in 50\% acetic acid on the dried smear and incubated the slide at $55^{\circ} \mathrm{C}$ for $5 \mathrm{~min}$. After washing the slide with sterile water, we allowed it to air-dry, and examined it using a Nikon ECLIPSE 50i microscope (Nikon Instruments Inc., Melville, NY, USA) with a 100× oil immersion objective.

\subsection{Determination of Cry Genes in Purported B. Megaterium, Using PCR}

Using template DNA from the mislabeled strain of B. megaterium and B. thuringiensis ATCC 35866 subsp. kurstaki, as a positive control, and a second strain of B. megaterium, ATCC 6458, as a negative control we used a Norgen Kit (Biotek, Thorold, ON, Canada), and the GoTaq green master mix (Promega, Madison, WI, USA) to detect the cry 1 gene via PCR. Amplification was performed using a BioRad C1000 Thermal Cycler (Bio Rad, Hercules, CA, USA). The optimized PCR conditions were a single denaturation step of $3 \mathrm{~min}$ at $94^{\circ} \mathrm{C} ; 25$ cycles of denaturation at $94{ }^{\circ} \mathrm{C}$ for $30 \mathrm{~s}$, annealing at $60^{\circ} \mathrm{C}$ for $1 \mathrm{~min}$, and extension at $72{ }^{\circ} \mathrm{C}$ for $1 \mathrm{~min}$; and final extension at $72{ }^{\circ} \mathrm{C}$ for $1 \mathrm{~min}$. The resulting PCR fragments were analyzed using a $2 \%$ E-gel precast agarose gel (Invitrogen, Thermo Fisher Scientific, Carlsbad, CA, USA) and the E-gel precast agarose electrophoresis system (Invitrogen). Purified sterile water and E-Gel1 kb Plus Ladder (Invitrogen) were added to the E-gel.

\subsection{Statistical Analysis}

This experiment was performed in triplicate $(n=3)$. These data were analyzed by repeated measures ANOVA using SAS 9.4 mixed procedure (SAS, Cary, NC, USA). Differences were accepted as statistically significant at $P<0.05$.

\section{Results and Discussion}

\subsection{Challenge in Products without Neutralization}

The products B, C, and D were individually inoculated with the selected strain of Bacillus spp. used in this study. The cells were mixed with the products and kept at room temperature for 30 min 
before aliquots of the inoculated samples were spiral plated on MLA. The surviving Bacillus cells are shown in Table 3.

There was no statistical difference $(P>0.05)$ among the strains; however, the type of preservatives in the given product formulation did have a significant $(P<0.05)$ impact on whether strains were detected. Growth of bacteria inoculated into Product B resulted in an estimated $2.48 \mathrm{log} \mathrm{CFU} / \mathrm{g}$, which was significantly greater $(P<0.05)$ than the cell growth found in Product D $(1.55 \log \mathrm{CFU} / \mathrm{g})$ or Product C (0.02 log MPN/g) (Figure 1). Intriguingly, the preservation system of Product $C$ was mainly based on essential oils and citric acid and yet this showed the highest inhibitory effect against the cells of Bacillus. Vegetative bacterial cells produced spores as a survival strategy in response to adverse environmental conditions. In this study, essential oils contained in Product $C$ inhibited the cells, and the cells were practically not detected after $24 \mathrm{~h}$ pre-enrichment at $30{ }^{\circ} \mathrm{C}$ and remained under the detection limit (0.04 log MPN/g). Voundi et al. [23] demonstrated that some essential oils had a bactericidal effect on vegetative cells and an inhibitory effect on both the germination and the outgrowth of Bacillus spores. Essential oils could damage a variety of targets within bacterial cells, particularly the membrane and cytoplasm, and in certain situations the action of these oils can completely alter the morphology of the cells [24]. In addition, various essential oils have been reported to have active components, which act as barriers for the germinant to bind to the receptors, and therefore they inhibit germination [25]. Product D, which displayed the next highest amount of bacterial growth, used potassium sorbate, sodium benzoate as preservatives, along with citric acid and plant extracts. Potassium sorbate and sodium benzoate are the sodium and potassium salts of sorbic acid and benzoic acid, respectively. Their modes of action are linked to their undissociated acidic forms. Those forms destroy the chemiosmotic balance across the cytoplasmic membrane, disrupting the membrane electrical potential by dissociating protons from the compounds, which then enter the cytoplasm of the cell [26]. The effectiveness of these organic acids is influenced by the inoculum level, temperature, $\mathrm{pH}$, and concentration [27]. The least effective preservative system, judged by the growth of spiked Bacillus cells, belonged to Product B, which was preserved with parabens (alkyl esters of P-hydroxybenzoic acid) and diazolidinyl urea (a formaldehyde releaser). Other studies suggest that the most likely mode of action for parabens and urea as cosmetic preservatives is the disruption of bacterial membrane potential; this disruption interferes with membrane transport or energy generation. Cells exposed to parabens leak their intracellular contents without showing apparent changes in cell structure, and such cells can recover should they then encounter a nutrient rich environment [28]. Formaldehyde derivatives cause irreversible folding of membrane proteins by forming methylene bridges between amino acids [29].

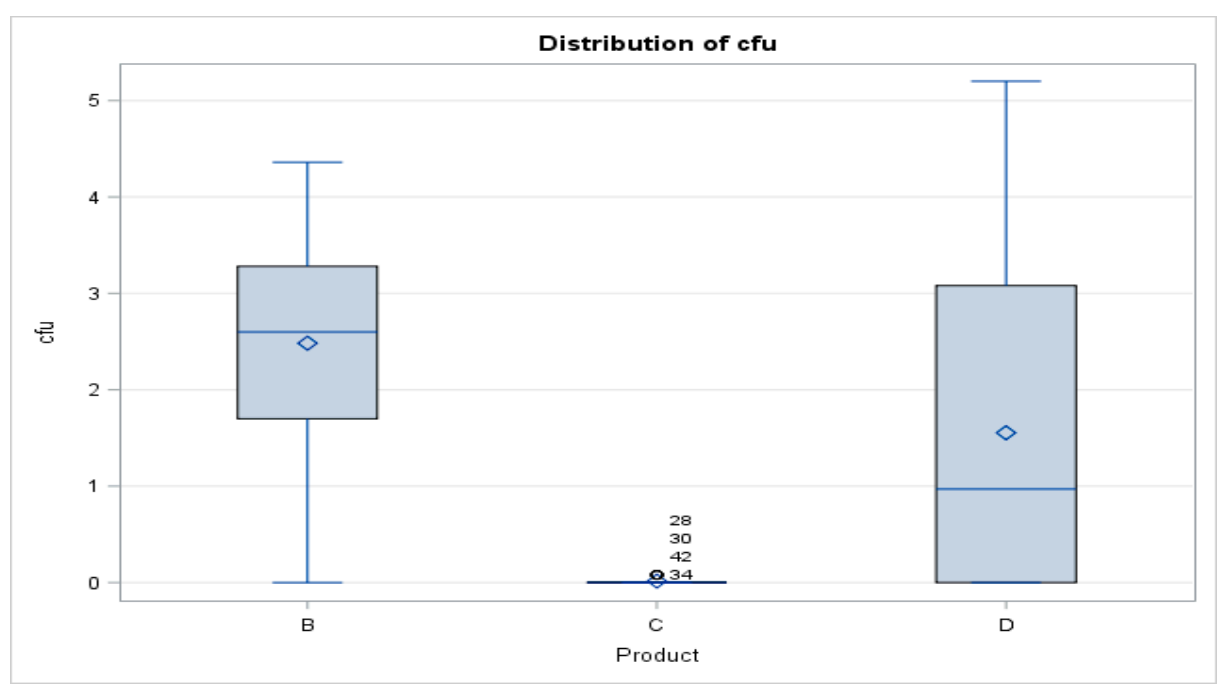

Figure 1. Bacillus strains in $\log \mathrm{CFU} / \mathrm{g}$ after exposure in Products $\mathrm{A}, \mathrm{B}$, and $\mathrm{C}$ without neutralizers. 
Table 3. Detection of Bacillus strains in log CFU/g after exposure to non-neutralized eye cream products.

\begin{tabular}{cccc}
\hline Strains & B & C $^{*}$ & D \\
\hline cereus ATCC 14579 & $1.99 \pm 0.83$ & NG & $0.13 \pm 0.23$ \\
cereus F 60006 & $2.56 \pm 0.80$ & $0.03 \pm 0.05$ & $0.87 \pm 1.50$ \\
cereus F4227A & $2.68 \pm 0.43$ & $0.05 \pm 0.05$ & $1.44 \pm 1.72$ \\
megaterium ATCC 6458 & $2.39 \pm 0.89$ & NG & $3.98 \pm 1.07$ \\
mycoides ATCC 6462 & $3.32 \pm 1.09$ & NG & $1.69 \pm 1.56$ \\
subtilis ATCC 15563 & $2.69 \pm 2.35$ & $0.03 \pm 0.05$ & $1.18 \pm 2.04$ \\
thuringiensis ATCC 35866 & $1.75 \pm 1.14$ & $\mathrm{NG}$ & $1.59 \pm 1.50$ \\
\hline
\end{tabular}

Data represent mean $\pm \mathrm{SD}, \mathrm{n}=3$; $\mathrm{NG}=$ no growth. Values are direct plate counts in log $\mathrm{CFU} / \mathrm{g} .{ }^{*}$ Values are MPN counts in $\log \mathrm{MPN} / \mathrm{g}$.

As shown in Table 3, spiked vegetative cells of Bacillus often were injured or killed after, exposure to non-neutralized eye cream products. Cells of B. cereus ATCC 14579, B. megaterium ATCC 6458, B. mycoides ATCC 6462, and B. thuringiensis ATCC 35866 showed no growth in Product C.

\subsection{Challenge Organisms in Products B, C, D Neutralized with T80, TS and T20}

For these challenges, each Bacillus strain was spiked into Products B, C, and D, which had been previously mixed with the neutralizers T80, TS, or T20. Similar to the preceding experiment, the initial count of each Bacillus strain showed no statistical difference $(P>0.05)$. The results are presented in Table 4. A mixed model was used to detect the factor effects on bacterial growth, and the resulting $P$ values are listed in Table 4 . The neutralizers, products, broths and plating media each significantly influenced $(P<0.05)$ the growth and detection of the Bacillus cells. The results are presented in Table 5 .

Table 4. Factors influencing the growth of Bacillus strains.

\begin{tabular}{|c|c|c|}
\hline \multicolumn{3}{|c|}{ Type 3 Tests of Fixed Effects } \\
\hline Effect & F Value & $\operatorname{Pr}>F$ \\
\hline Product & 99.83 & $<0.0001$ \\
\hline Neutralizer & 183.03 & $<0.0001$ \\
\hline Bacteria & 0.03 & 0.9998 \\
\hline Broth & 10.73 & 0.0011 \\
\hline Media & 19.42 & $<0.0001$ \\
\hline
\end{tabular}

\subsection{Neutralizers}

The spiked cells grew significantly better in the samples neutralized with T80 (4.10 log CFU/g) as opposed to TS $(3.72 \log$ CFU/g), while the growth of the cells in products neutralized with TS was significantly $(P<0.05)$ better than growth in products neutralized using T20 $(1.46 \log \mathrm{CFU} / \mathrm{g})$ $(P<0.05)$. Our results demonstrate that the neutralizers T80 and TS especially in Products B and D more effectively deactivated the preservatives. These findings confirm early observations by Marx and coworkers [30] who found a direct relationship between the degree to which a neutralizer was hydrophobic and its neutralization effectiveness: T20, the least hydrophobic neutralizer, was less able to inactivate preservatives than T60, which, in turn, was both less hydrophobic and less effective than T80. In our study, T80 was a better neutralizer than the combination of T60 + Span 80, although that combination was more effective than T20 alone. Interestingly, our previous studies had shown no difference between neutralizing effects of T80 and TS after $30 \mathrm{~min}$ in eye cream samples preserved with parabens for the enumeration of B. cereus [31]. The same observation was made in this study with Products B and D. However, T80 yielded significantly higher results than TS in Product C $(P<0.05)$, which is essentially preserved with plant extracts. This result implies that TS may not neutralize the essential oils as effectively as T80 can. Wedderburn [32] had reported T80 exhibited a great hydrophobicity that might allow better partitioning of the micelles, which would contribute to 
more effective neutralization of products' preservatives. The addition of Span might have enabled better homogenization of ingredients, but it did not influence how effectively the essential oils were neutralized. It is possible that the means by which essential oils are inactivated by TS is different from how parabens or the organic acids and their salts can be neutralized.

Table 5. Detection of Bacillus ${ }^{*}$ strains in $\log$ CFU/g on BACARA and MYP after exposure to neutralized eye cream products.

\begin{tabular}{|c|c|c|c|c|c|c|c|c|}
\hline \multirow{2}{*}{ Neutralizers } & \multirow{2}{*}{ Strains } & \multirow{2}{*}{ Broth } & \multicolumn{2}{|c|}{ B } & \multicolumn{2}{|c|}{$\mathrm{C}$} & \multicolumn{2}{|c|}{ D } \\
\hline & & & BACARA & MYP & BACARA & MYP & BACARA & MYP \\
\hline \multirow[t]{14}{*}{$\mathrm{T} 80$} & \multirow[t]{2}{*}{4227} & MLB & $2.0 \pm 1.9$ & $3.5 \pm 0.4$ & $3.4 \pm 0.6$ & $4.1 \pm 0.2$ & $4.9 \pm 0.2$ & $4.9 \pm 0.2$ \\
\hline & & TAT & $2.1 \pm 1.5$ & $3.5 \pm 0.3$ & $3.6 \pm 0.6$ & $4.1 \pm 0.5$ & $5.0 \pm 0.3$ & $4.9 \pm 0.3$ \\
\hline & \multirow[t]{2}{*}{60006} & MLB & $2.1 \pm 1.9$ & $3.6 \pm 0.6$ & $3.9 \pm 0.7$ & $4.4 \pm 0.6$ & $5.2 \pm 0.0$ & $5.2 \pm 0.0$ \\
\hline & & TAT & $2.7 \pm 1.7$ & $3.3 \pm 0.2$ & $4.1 \pm 0.8$ & $4.5 \pm 0.7$ & $5.2 \pm 0.0$ & $5.2 \pm 0.0$ \\
\hline & \multirow[t]{2}{*}{14579} & MLB & $3.9 \pm 0.1$ & $3.9 \pm 0.2$ & $3.5 \pm 0.6$ & $4.3 \pm 0.4$ & $5.3 \pm 0.1$ & $5.3 \pm 0.0$ \\
\hline & & TAT & $4.3 \pm 0.4$ & $4.1 \pm 0.5$ & $4.1 \pm 0.7$ & $4.4 \pm 0.6$ & $5.2 \pm 0.2$ & $5.3 \pm 0.0$ \\
\hline & \multirow[t]{2}{*}{6458} & MLB & $2.5 \pm 2.1$ & $3.9 \pm 0.2$ & $2.8 \pm 2.1$ & $3.0 \pm 2.3$ & $5.2 \pm 0.1$ & $5.1 \pm 0.0$ \\
\hline & & TAT & $3.2 \pm 1.7$ & $4.0 \pm 0.1$ & $2.9 \pm 1.7$ & $3.9 \pm 0.8$ & $5.2 \pm 0.1$ & $5.0 \pm 0.2$ \\
\hline & \multirow[t]{2}{*}{6264} & MLB & $3.4 \pm 0.5$ & $3.7 \pm 0.5$ & $2.7 \pm 2.4$ & $3.0 \pm 2.6$ & $5.0 \pm 0.4$ & $5.0 \pm 0.5$ \\
\hline & & TAT & $3.4 \pm 1.5$ & $3.8 \pm 0.8$ & $3.8 \pm 0.4$ & $4.0 \pm 0.9$ & $5.1 \pm 0.4$ & $5.1 \pm 0.4$ \\
\hline & \multirow[t]{2}{*}{15563} & MLB & NG & $3.8 \pm 0.5$ & NG & $3.8 \pm 1.5$ & NG & $4.5 \pm 0.4$ \\
\hline & & TAT & NG & $4.2 \pm 0.4$ & NG & $4.2 \pm 0.8$ & NG & $4.5 \pm 0.3$ \\
\hline & \multirow[t]{2}{*}{35866} & MLB & $2.2 \pm 1.5$ & $3.6 \pm 0.2$ & $3.8 \pm 0.5$ & $4.5 \pm 0.3$ & $5.1 \pm 0.1$ & $5.0 \pm 0.1$ \\
\hline & & TAT & $3.6 \pm 0.2$ & $4.0 \pm 0.8$ & $4.3 \pm 0.4$ & $4.6 \pm 0.5$ & $5.1 \pm 0.1$ & $5.0 \pm 0.1$ \\
\hline \multirow[t]{14}{*}{$\mathrm{T} 20$} & \multirow[t]{2}{*}{4227} & MLB & $2.0 \pm 0.7$ & $1.6 \pm 1.4$ & $0.5 \pm 0.4$ & $0.9 \pm 1.0$ & $2.4 \pm 0.8$ & $3.2 \pm 0.6$ \\
\hline & & TAT & $1.9 \pm 1.0$ & $2.2 \pm 1.3$ & $0.4 \pm 0.5$ & $0.4 \pm 0.5$ & $2.4 \pm 0.4$ & $2.7 \pm 0.7$ \\
\hline & \multirow[t]{2}{*}{60006} & MLB & $1.4 \pm 2.4$ & $0.9 \pm 1.6$ & NG & NG & $3.0 \pm 1.2$ & $2.6 \pm 1.0$ \\
\hline & & TAT & $0.6 \pm 1.0$ & $0.6 \pm 1.0$ & $0.2 \pm 0.2$ & $0.7 \pm 1.1$ & $1.8 \pm 1.1$ & $2.2 \pm 1.5$ \\
\hline & \multirow[t]{2}{*}{14579} & MLB & $1.3 \pm 1.3$ & $1.3 \pm 1.3$ & NG & NG & $2.5 \pm 0.7$ & $2.9 \pm 0.8$ \\
\hline & & TAT & $1.2 \pm 1.6$ & $1.2 \pm 1.6$ & NG & NG & $2.9 \pm 0.6$ & $3.0 \pm 0.6$ \\
\hline & \multirow[t]{2}{*}{6458} & MLB & $0.4 \pm 0.6$ & $0.4 \pm 0.6$ & NG & $0.3 \pm 0.5$ & $3.4 \pm 0.3$ & $3.6 \pm 0.2$ \\
\hline & & TAT & $0.6 \pm 0.5$ & $0.6 \pm 0.6$ & $0.2 \pm 0.2$ & $0.2 \pm 0.2$ & $3.2 \pm 1.3$ & $3.4 \pm 1.2$ \\
\hline & \multirow[t]{2}{*}{6264} & MLB & $2.3 \pm 1.8$ & $2.3 \pm 1.8$ & NG & NG & $2.5 \pm 0.6$ & $2.5 \pm 0.1$ \\
\hline & & TAT & $1.6 \pm 1.6$ & $1.6 \pm 1.6$ & NG & NG & $3.6 \pm 1.2$ & $3.3 \pm 1.6$ \\
\hline & \multirow[t]{2}{*}{15563} & MLB & NG & $2.6 \pm 2.0$ & NG & $0.3 \pm 0.5$ & NA & $2.7 \pm 0.8$ \\
\hline & & TAT & NG & $1.1 \pm 1.3$ & NG & $0.4 \pm 0.6$ & NA & $2.8 \pm 2.4$ \\
\hline & \multirow{2}{*}{35866} & MLB & $0.9 \pm 0.7$ & $0.8 \pm 0.7$ & NG & NG & $2.7 \pm 0.9$ & $2.9 \pm 1.1$ \\
\hline & & TAT & $0.5 \pm 0.5$ & $0.7 \pm 0.8$ & NG & NG & $2.7 \pm 0.8$ & $3.2 \pm 1.0$ \\
\hline \multirow[t]{14}{*}{ TS } & 4227 & MLB & $1.8 \pm 1.8$ & $3.5 \pm 0.6$ & $2.3 \pm 1.4$ & $2.7 \pm 1.7$ & $4.9 \pm 0.2$ & $4.8 \pm 0.2$ \\
\hline & & TAT & $2.0 \pm 1.8$ & $3.3 \pm 0.6$ & $2.3 \pm 1.5$ & $3.1 \pm 1.0$ & $4.8 \pm 0.3$ & $4.8 \pm 0.2$ \\
\hline & 60006 & MLB & $3.0 \pm 0.4$ & $3.7 \pm 0.1$ & $1.7 \pm 2.1$ & $2.4 \pm 1.7$ & $5.2 \pm 0.2$ & $5.1 \pm 0.1$ \\
\hline & & TAT & $2.8 \pm 1.8$ & $3.6 \pm 0.1$ & $2.3 \pm 1.7$ & $2.5 \pm 2.0$ & $5.2 \pm 0.0$ & $5.1 \pm 0.1$ \\
\hline & 14579 & MLB & $3.5 \pm 0.1$ & $3.8 \pm 0.2$ & $0.8 \pm 1.3$ & $1.1 \pm 1.8$ & $5.2 \pm 0.1$ & $5.2 \pm 0.1$ \\
\hline & & TAT & $3.5 \pm 1.5$ & $4.3 \pm 0.7$ & $0.2 \pm 1.4$ & $1.3 \pm 1.6$ & $5.2 \pm 0.2$ & $5.3 \pm 0.1$ \\
\hline & 6458 & MLB & $3.0 \pm 1.8$ & $3.9 \pm 0.3$ & $2.0 \pm 1.3$ & $2.7 \pm 1.8$ & $5.1 \pm 0.1$ & $5.0 \pm 0.1$ \\
\hline & & TAT & $3.1 \pm 1.8$ & $4.0 \pm 0.2$ & $2.4 \pm 1.0$ & $2.7 \pm 1.3$ & $5.1 \pm 0.1$ & $5.1 \pm 0.1$ \\
\hline & 6264 & MLB & $4.0 \pm 0.7$ & $4.0 \pm 0.8$ & $2.2 \pm 1.5$ & $2.8 \pm 1.8$ & $5.0 \pm 0.3$ & $4.9 \pm 0.3$ \\
\hline & & TAT & $3.2 \pm 1.5$ & $4.0 \pm 0.6$ & $2.2 \pm 0.7$ & $3.1 \pm 1.4$ & $5.0 \pm 0.3$ & $5.0 \pm 0.3$ \\
\hline & 15563 & MLB & NA & $3.5 \pm 0.8$ & NA & $2.5 \pm 2.3$ & NA & $4.5 \pm 1.0$ \\
\hline & & TAT & NA & $4.3 \pm 0.7$ & NA & $2.6 \pm 2.4$ & NA & $4.4 \pm 0.6$ \\
\hline & 35866 & MLB & $2.7 \pm 2.3$ & $3.9 \pm 0.6$ & $1.9 \pm 1.8$ & $2.5 \pm 2.2$ & $5.1 \pm 0.0$ & $5.0 \pm 0.1$ \\
\hline & & TAT & $2.8 \pm 2.5$ & $3.9 \pm 0.6$ & $1.8 \pm 1.3$ & $2.8 \pm 2.1$ & $5.0 \pm 0.1$ & $5.0 \pm 0.1$ \\
\hline
\end{tabular}

${ }^{*}$ B. cereus $\mathrm{F} 4227 \mathrm{~A}$, B. cereus $\mathrm{F} 60006$, B. cereus ATCC 14579, B. labeled megaterium ATCC 6458, B. mycoides ATCC 6264, B. subtilis ATTC 15563, B. thuringiensis ATCC 35866. $5 \log$ CFU/mL of each cell. Data represent mean $\pm \mathrm{SD}, n=3 ; \mathrm{NG}=$ no growth. Values are direct plate counts in log CFU/g. MLB: Modified Letheen Broth;

TAT: Tryptone-Azolectin-Tween; T20: Tween 20, T80: Tween 80; TS: blend of Tween 60 and Span 80.

\subsection{Comparing the Effects of Neutralizers by Products}

The bacterial growth in the T80 and TS conditions was similar: 3.50 and $3.58 \log$ CFU/g in Product B, respectively; 4.96 and $4.91 \log$ CFU/g in Product D, respectively $(P>0.05)$. However, in Product $C$, the amount of bacterial growth in the T80 samples was significantly higher (3.82 log CFU/g) than in 
T60 samples (2.69 log CFU/g). We found T80 was the best neutralizer in all three products. T20 was the least effective $(1.28,0.15$ and $2.93 \mathrm{log}$ CFU/g in product $\mathrm{B}, \mathrm{C}, \mathrm{D}$, respectively).

\subsection{Best Diluting Broth Used in Conjunction with the Neutralizer T80}

We used the same mixed model to test the effects of broth composition and plating media when T80 was used as a neutralizer. As shown in Table 6, each of these variables: product, broth, and plating media, had significant influence on the likelihood of bacterial recovery. The estimated average bacterial population when TAT was used was significantly higher, $4.18 \mathrm{log}$ CFU/g, compared to the population in MLB, which was $3.97 \log C F U / g(P<0.05)$. This result indicated that using TAT $+\mathrm{T} 80$ leads to a higher recovery of the Bacillus cells than the combination of MLB + T80.

Table 6. Factors influencing the growth of bacteria using the neutralizer T80.

\begin{tabular}{|c|c|c|}
\hline \multicolumn{3}{|c|}{ Type 3 Tests of Fixed Effects } \\
\hline Effect & $F$ Value & $\operatorname{Pr}>F$ \\
\hline Product & 24.84 & $<0.0001$ \\
\hline Bacteria & 0.67 & 0.6704 \\
\hline Broth & 16.14 & $<0.0001$ \\
\hline Media & 14.67 & $<0.0001$ \\
\hline
\end{tabular}

\subsection{Best Plating Media for Use with T80}

The average amount of bacterial growth on MYP was significantly higher $(P<0.05)$ (4.25 log CFU/g) compared to the average population on BARACA (3.84 log CFU/g).

The amount of bacterial growth from spiked samples of Product $D$ was the same regardless of plating media $(P>0.05)$ but there were significant differences between outcomes for Products $B$ and $C(P<0.05)$. In Product $B$, more growth was observed on MYP than on BACARA. It is possible that some of the ingredients in the formulation of Product B might interfere with the selective agents used in BACARA. This result observed with Product B is different from the results obtained with other products which raise the important question of whether detection of $B$. cereus on BACARA might depend on the composition of a specific cosmetic. We have also noticed that the loss of lecithinase expression by the $B$. cereus colonies: the typical white halo around colonies on these plates was absent. Studies have demonstrated that the lecithinase production of B. cereus is substrate dependent [33]. Kushner [34,35], for example, reported that the presence of alcohols and enzymes in the growth medium inhibited the synthesis of lecithinase by growing B. cereus. In our study, the synthesis of lecithinase might have been affected by some substances in the formulation of Products B.

\subsection{Identification of Mislabeled Strain of Megaterium}

MYP and BACARA agars are limited to differentiate among the members of $B$. cereus group; further alternative approaches for differentiation are carried out using microscopy or molecular methods. B. thuringiensis produces crystalline inclusion bodies during sporulation that can be seen under a microscope. This is the best criteria to distinguish $B$. thuringiensis from other related species in the Bacillus cereus group. The strain of Bacillus labeled B. megaterium ATCC 6258 grew on the chromogenic plate BACARA [36] but also on MYP with typical B. cereus features suggesting the strain actually was a member of the cereus group (Figure 2). Further investigation, including staining of this suspect strain using Brilliant Blue R250 and TB carbofuchsin (FDA-BAM method) revealed the presence of parasporal bodies indicating that the strain had been mislabeled. These staining patterns confirmed this strain as B. thuringiensis. 


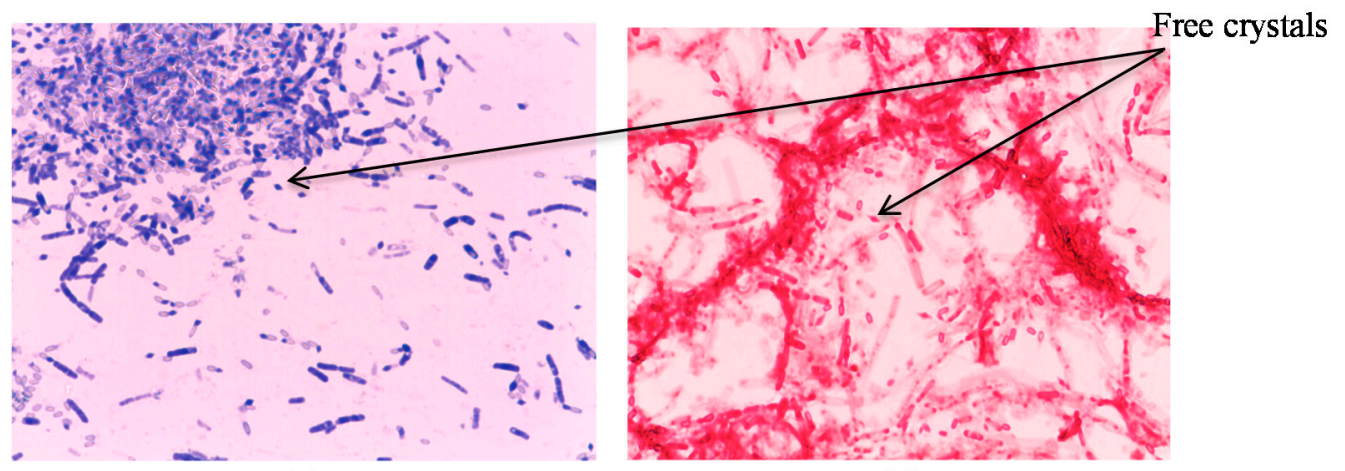

(a)

(b)

Figure 2. Nikon ECLIPSE 50i microscope indicating crystals using Brilliant Blue R 250 staining (a) and BAM method (b); Oil immersion magnification $100 \times$.

\subsection{Determination of Cry Genes by PCR}

The morphology, size, and number of parasporal bodies may vary among the strains. However, four distinct crystal morphologies are apparent: the bipyramidal crystal, related to Cry 1 proteins [37]; cuboidal inclusions related to Cry 2 proteins and usually associated with bipyramidal crystals [38]; amorphous and composite crystals related to Cry 4 and Cyt proteins [39]; and flat square crystals related to Cry 3 proteins $[40,41]$. Spherical and irregular crystal shapes can also be observed in some strains of $B$. thuringiensis [42].

As we were able to locate bipyramidal crystals under a microscope, we ran PCR analyses to confirm the presence of the cry 1 gene in the mislabeled B. megaterium. We used B. thuringiensis, B. thuringiensis subsp. kurtaski ATCC 35866 (positive control) and a newly purchased B. megaterium ATCC 6458 for this analysis. The template DNA of the three strains was amplified using the universal primers for the cry 1 gene, which produce PCR products of expected size around $270 \mathrm{bp}$ for the positive control (lane 3) and the mislabeled B. megaterium (lane 4). As shown in Figure 3, the newly purchased strain of B. megaterium presented no such band (lane 2).

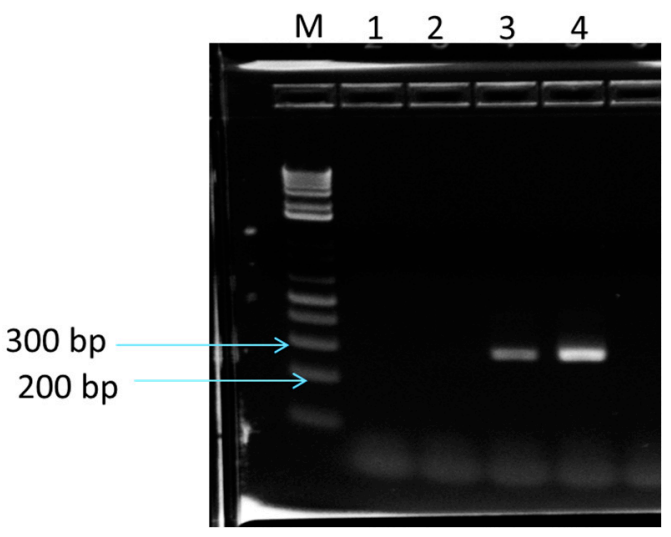

Figure 3. E-Gel (2\% Agarose gel) electrophoresis of PCR products for cry 1 genes. Lane M: E-Gel $1 \mathrm{~Kb}$ Plus DNA Ladder; Lane 1: sterile water, Lane 2: B. megaterium ATCC 6458; Lane 3: B. thuringiensis subs. kurstaki ATCC 35866 as cry 1 positive control; Lane 4: strain mislabeled B. megaterium.

\section{Conclusions}

Our study showed that the optimized culture conditions for detecting Bacillus spp. in eye cream depends upon multiple factors: the product, dilution broths, neutralizer, and plating media. We found the combination of TAT + T80 allowed better recoveries of Bacillus strains especially in products 
naturally preserved. In addition, the preservation system of Product $C$ mainly based on essential oils and citric acid showed the highest inhibitory effect against the cells of Bacillus among the three tested products. In light of these findings, follow-up studies will examine the use of the FDA-BAM method using MLB + T80 and TAT + T80 for the detection of Bacillus spp. and other pathogenic bacteria in eye cream and powder products with the goal of developing a cultural method of detection of bacteria in eye cream products.

BACARA and MYP demonstrated that the mislabeled strain of B. megaterium belonged to the member of $B$. cereus group, and the microscopy and molecular methods were necessary to further differentiate the strain as B. thuringiensis.

Acknowledgments: This work was supported by the Office of Cosmetics and Colors. We thank the team Prepmedia for preparing the media used in this study and Lili Fox Vélez for scientific writing support.

Author Contributions: Nadine Yossa and Thomas Hammack conceived and designed the experiments; Nadine Yossa and Gabriela Arce performed the experiment; Lanlan Yin analysed the data; Nadine Yossa wrote the paper. Thomas Hammack, Mei-Chiung Jo Huang, Rebecca Bell, Sandra Tallent, and Eric Brown contributed to the elaboration of the paper by giving pertinent suggestions and making corrections. James Smiley contributed by preparing the media and the reagents necessary for the execution of the study.

Conflicts of Interest: The authors declare no conflict of interest. The founding sponsors had no role in the design of the study; in the collection, analyses, or interpretation of data; in the writing of the manuscript, and in the decision to publish the results.

\section{References}

1. Wong, S.; Street, D.; Delgado, S.I.; Klontz, K.C. Recalls of foods and cosmetics due to microbial contamination reported to the U.S. Food and drug Administration. J. Food Prot. 2000, 63, 1113-1116. [CrossRef] [PubMed]

2. Neza, E.; Centini, M. Microbiologically contaminated and over-preserved cosmetic products according Rapex 2008-2014. Cosmetics 2016, 3, 3. [CrossRef]

3. Sutton, S.V.W. Antimicrobial preservative efficacy and microbial content testing. In Cosmetic Microbiology: A Practical Approach, 2nd ed.; Geis, P.A., Ed.; CRC Press: Boca Raton, FL, USA, 2006.

4. EFSA Panel on biological hazards (BIOHAZ). Scientific opinion on the risks for public health related to the presence of Bacillus cereus and other Bacillus spp. including Bacillus thuringiensis in foodstuffs. EFSA J. 2016, 14, 93.

5. International Organization for Standardization (ISO). Microbiology of Food and Animal Feeding Stuffs-Horizontal Method for the Enumeration of Presumptive Bacillus cereus—Colony Count Technique at $30^{\circ} \mathrm{C}$; Beuth Verlang Gmbh: Köln, Germany, 2005.

6. International Organization for Standardization (ISO). Microbiology of Food and Animal Feeding Stuffs-Horizontal Method for the Determination of Low Numbers of Presumptive Bacillus cereus-Most Probable Number Technique and Detection Method (ISO21871:2006); Beuth Verlang Gmbh: Köln, Germany, 2006.

7. Bottone, E.J. Bacillus cereus, a volatile human pathogen. Clin. Microbiol. Rev. 2010, 23, 382-398. [CrossRef] [PubMed]

8. Moyer, L.A.; Ramadan, R.T.; Novosad, B.D.; Callegan, M.C. Bacillus cereus—Induced permeability of the blood ocular barrier during experimental endophthalmitis. Invest. Ophthalmol. Vis. Sci. 2009, 50, 3783-3793. [CrossRef] [PubMed]

9. Donzis, P.B.; Mondino, B.J.; Weisman, B.A. Bacillus keratitis with contaminated contact lens case system. Am. J. Ophthaimol. 1988, 105, 194-197.

10. Van Setten, G.B.; Tervo, T.; Tarkkanen, A. Acute keratitis and contamination of contact lens care systems with B. cereus. Klin. Monbl. Augenheilkd. 1989, 195, 28-31. [PubMed]

11. Pinna, A.; Sechi, L.A.; Zanetti, S.; Usai, D.; Delogu, G.; Cappuccinelli, P.; Carta, F. Bacillus cereus keratitis associated with contact lens wear. Ophthalmology 2001, 108, 1830-1834. [CrossRef]

12. Gemdo Cosmetics, Inc. 4/16/15. Available online: https://www.fda.gov/ICECI/EnforcementActions/ WarningLetters/ucm443701.htm (accessed on 12 December 2017).

13. Import Alert 53-17. Available online: https://www.accessdata.fda.gov/cms_ia/importalert_136.html (accessed on 12 December 2017). 
14. Pitt, T.L.; McClure, J.; Parker, M.D.; Amézouita, A.; McClure, P.J. Bacillus cereus in personal care products: Risk to consumers. Int. J. Cosmet. Sci. 2015, 37, 165-174. [CrossRef] [PubMed]

15. Rieger, M.M. Surfactant Chemistry and Classification. In Surfactants in Cosmetics, 2nd ed.; Rieger, M., Rhein, L.D., Eds.; Marcel Dekker: New York, NY, USA, 1997.

16. Orth, D.S. Inactivation of Preservatives by Surfactants. In Surfactants in Cosmetics, 2nd ed.; Rieger, M., Rhein, L.D., Eds.; Marcel Dekker: New York, NY, USA, 1997.

17. English, D.J. Factors in selecting and testing preservatives in product. In Cosmetic and Drug Microbiology; Orth, D.S., Kabara, J.J., Denyer, S.P., Tan, S.K., Eds.; Informa Healthcare: New York, NY, USA, 2006.

18. Frentzel, H. Determination, Characterization and Survival of Bacillus Cereus Group Members in Spices and Herbs. Ph.D. Thesis, Freien Universität Berlin, Berlin, Germany, June 2017.

19. Cosmetic, Toiletry and Fragrance Association. Available online: http://cosmetictestlabs.com/ctfa_m-4_ summary.html (accessed on 16 February 2015).

20. BAM Appendix 2: Most Probable Number from Serial Dilutions. Available online: https://www.fda.gov/ Food/FoodScienceResearch/LaboratoryMethods/ucm109656 (accessed on 13 December 2017).

21. FDA. Bacteriological Analytical Manuel (BAM). Bacillus cereus. Available online: http://www.fda.gov/ Food/FoodScienceResearch/LaboratoryMethods/ucm070875.htm (accessed on 13 December 2017).

22. Ammons, D.; Rampersad, J.; Khan, A. Usefulness of staining parasporal bodies when screening for Bacillus thuringiensis. J. Invertebr. Pathol. 2002, 79, 203-204. [PubMed]

23. Voundi, S.O.; Nyegue, M.; Lazar, I.; Raducanu, D.; Foe Ndoye, F.; Stamate, M.; Etoa, F.-X. Effect of essential oils on germination and growth of some pathogenic and spoilage spore-forming bacteria. Foodborne Pathog. Dis. 2015, 12, 551-559. [CrossRef] [PubMed]

24. Nazarro, F.; Fratianni, F.; De Martino, L.; Coppola, R.; De Feo, V. Effect of essential oils on pathogenic bacteria. Pharmaceuticals 2013, 6, 1451-1474. [CrossRef] [PubMed]

25. Hayley, A.L.; Palombo, E.A. Activity of essential oils against Bacillus subtilis spores. J. Microbiol. Biotechnol. 2009, 19, 1590-1595.

26. Geis, P.A. Common cosmetic preservatives. In Cosmetic Microbiology: A Practical Approach, 2nd ed.; Geis, P.A., Ed.; CRC Press: Boca Raton, FL, USA, 2006.

27. Ibarra, F.; Johnson, C. Natural Preservation from Concepts in Nature-Microorganisms and Cosmetics; Allured Books: Carol Stream, IL, USA, 2009.

28. Sox, T.E. Mechanisms of action of cosmetic preservatives. In Cosmetic Microbiology: A Practical Handbook; Brannan, D.K., Ed.; CRC Press: Boca Raton, FL, USA, 1997.

29. Cummings, P.; Goldstein, M. Preservatives boosters: Up against the wall. In Cosmetic Microbiology: A Practical Approach, 2nd ed.; Geis, P.A., Ed.; CRC Press: Boca Raton, FL, USA, 2006.

30. Marx, H.; Sabalitschka, T.; Boehm, E. Behavior of antimicrobial materials in nonionic systems. Am. Perfum. Cosmet. 1968, 83, 39-47.

31. Yossa, N.; Arce, G.; Huang, M.-C.J.; Yin, L.; Brown, E.; Hammack, T. Factors of detection of Bacillus cereus strains in eye cream. Int. J. Cosmet. Sci. 2017, 39, 179-187. [CrossRef] [PubMed]

32. Wedderburn, D.L. Preservation of toilet preparations containing nonionics. J. Soc. Cosmet. Chem. 1957, 210-228.

33. Sharaf, E.F.; El-Sayed, W.S.; Abosaif, R.M. Lecithicinase-producing bacteria in commercial and home-made foods: Evalustion of toxic propertis and identification of potent producers. J. Taibah Univ. Sci. 2014, 8, 207-215. [CrossRef]

34. Kushner, D.J. The effect of alcohols on the synthesis of lecithinase by Bacillus cereus. Nature 1957, 179, 781-782. [CrossRef] [PubMed]

35. Kushner, D.J. The effect of alcohols on the synthesis of lipase, lecithinase and other enzymes by Bacillus cereus. Biochem. J. 1960, 75, 386-395. [CrossRef] [PubMed]

36. Tallent, S.M.; Kotewicz, K.M.; Strain, E.A.; Bennett, R.W. Efficient isolation and identification of Bacillus cereus group. J. AOAC Int. 2012, 95, 446-451. [CrossRef] [PubMed]

37. Aronson, A.I.; Fritz-James, P. Structures and morphogenesis of the bacterial pore coat. Bacteriol. Rev. 1976, 40, 360-402. [PubMed]

38. Ohba, M.; Aizawa, K. Distribution of Bacillus thuringiensis in soils of Japan. J. Invertebr. Pathol. 1986, 47, 277-282. [CrossRef] 
39. Federici, B.A.; Luethy, P.; Ibarra, J.E. Parasporal Body of Bacillus thuringiensis Subs. Israelensis: Structure, Protein Composition and Toxicity. In Bacterial Control of Mosquitos and Blackflies: Biochemistry, Genetics and Applications of Bacillus thuringiensis and Bacillus sphaericus; de Barjac, H., Sutherland, D.J., Eds.; Rutgers University Press: New Brunswick, NJ, USA, 1990.

40. Herrnstand, C.H.; Soares, G.G.; Wilcox, E.R.; Edwards, D.I. A new strain of Bacillus thuringiensis with activity against coleopteran insects. Nat. Biotechnol. 1986, 4, 305-308. [CrossRef]

41. Lopez-meza, J.E.; Ibarra, J.E. Characterization of a novel strain of Bacillus thuringiensis. Appl. Environ. Microbiol. 1996, 62, 1306-1310. [PubMed]

42. Arrieta, G.; Espinoza, H.A. Characterization of Bacillus thuringiensis strain collection isolated from diverse Costa Rican natural ecosystems. Rev. Biol. Trop. 2006, 54, 13-27. [CrossRef] [PubMed]

2017 by the authors. Licensee MDPI, Basel, Switzerland. This article is an open access article distributed under the terms and conditions of the Creative Commons Attribution (CC BY) license (http:/ / creativecommons.org/licenses/by/4.0/). 